\title{
Staffing in Ontario's Long-Term Care Homes: Differences by Profit Status and Chain Ownership*
}

\author{
Amy T. Hsu, 1,2 Whitney Berta, ${ }^{1}$ Peter C. Coyte, ${ }^{1,2}$ and Audrey Laporte ${ }^{1,2}$
}

\begin{abstract}
RÉSUMÉ
L'Ontario compte la plus forte proportion des maisons de soins infirmiers à but lucratif au Canada. Ces maisons de soins infirmiers, connus en Ontario comme maisons de soins de longue durée (SLD), offrent 24 heures de soins de garde et de soins infirmiers aux personnes qui sont incapables de vivre de façon autonome. De plus en plus, ces installations fonctionnent aussi comme membres de chaînes de multi-établissements, mais elles n'ont pas été largement étudiées au Canada. En utilisant des données longitudinales (1996-2011) de 1'Enquête sur les établissements de soins résidentiels $(n=627)$, notre analyse a révélé des différences perceptibles dans les niveaux du personnel selon le statut de profit et de l'affiliation aux chaînes. Nous avons trouvé que les maisons SLD à but lucratif - en particulier celles appartenant à une chaîne - ont fournies significativement moins d'heures de soins, après l'ajustement des variations de la nécessité des soins pour les résidents. Les résultats de cette étude offrent des nouveaux renseignements sur l'impact de la structure organisationnelle sur les niveaux de personnel dans les foyers de SLD de l'Ontario, et ont des implications pour d'autres juridictions où la présence de plus en plus d'opérateurs privés affiliés à des chaînes a été observée.
\end{abstract}

\begin{abstract}
Ontario has the highest proportion of for-profit nursing homes in Canada. These facilities, which are known in Ontario as long-term care (LTC) homes, offer 24-hour custodial as well as nursing care to individuals who cannot live independently. Increasingly, they are also operating as members of multi-facility chains. Using longitudinal data (1996-2011) from the Residential Care Facilities Survey $(n=627)$, our analysis revealed discernible differences in staffing levels by profit status and chain affiliation. We found for-profit LTC homes - especially those owned by a chain organization - provided significantly fewer hours of care, after adjusting for variation in the residents' care needs. Findings from this study offer new information on the impact of organizational structure on staffing levels in Ontario's LTC homes and have implications for other jurisdictions where a growing presence of private, chain-affiliated operators has been observed.
\end{abstract}

1 Institute of Health Policy, Management and Evaluation (IHPME), University of Toronto

2 The Canadian Centre for Health Economics (CCHE), University of Toronto

* The research presented in this article was financially supported by grant funding provided to Audrey Laporte and Whitney Berta through the Canadian Institutes of Health Research (CIHR), grant \#66997. We would like to extend our gratitude to the staff at the Toronto Region Research Data Centre (Toronto RDC), which is part of the Canadian Research Data Centre Network (CRDCN), for their assistance with data access. Although this research was conducted using data collected by Statistics Canada, the conclusions and opinions presented here belong solely to the authors and do not represent the views of the organization, the CRDCN, or of its partners. We also wish to thank the participants of the Canadian Centre for Health Economics (CCHE) seminar series, Tracy Li, as well as two anonymous reviewers for their helpful comments and suggestions on earlier versions of this work.

Manuscript received: / manuscrit reçu : 29/01/15

Manuscript accepted: / manuscrit accepté : 30/07/15

Mots clés : vieillissment, maisons de soins infirmiers, personnel, propriété à but lucratif, organisations de chaîne, soins à longue durée

Keywords: aging, nursing homes, staffing, for-profit ownership, chain organizations, long-term care

La correspondance et les demandes de tire-à-part doivent être adressées à: / Correspondence and requests for offprints should be sent to:

Amy T. Hsu, Ph.D.

Institute of Health Policy, Management and Evaluation (IHPME)

University of Toronto 
Health Sciences Building

155 College Street, Suite 425

Toronto, ON M5T 3M6

(amy.hsu@mail.utoronto.ca)

\section{Introduction}

Long-term care (LTC) homes in Ontario are publicly funded facilities that provide access to 24-hour nursing and personal care, primarily to older adults who are unable to live independently in their own homes. In other Canadian provinces, these facilities may be known as personal care homes, nursing facilities, LTC facilities, special care homes, or residential care facilities for the aged. In the extant literature, this type of care setting is most commonly known as a nursing home.

In this descriptive study, we examined the effect of profit status and chain affiliation on staffing levels in Ontario's LTC homes. The motivation for investigating these relationships stems from past empirical research on the use of health human resources in this setting, and their purported associations to outcomes of care. Since Ontario has the highest percentage of publicly funded for-profit (FP) facilities in Canada (Blomqvist \& Busby, 2012), these observations are of particular relevance.

\section{Existing Literature}

Many studies have found that not-for-profit (NFP) nursing homes provide more hours of care, and employ a greater proportion of registered nurses (RNs) than FP nursing homes (Banaszak-Holl \& Hines, 1996; Berta, Laporte, \& Valdmanis, 2005; Berta, Laporte, Zarnett, Valdmanis, \& Anderson, 2006; Bravo, Charpentier, Dubois, De Wals, \& Émond, 1998; Comondore et al., 2009; Harrington, Olney, Carrillo, \& Kang, 2012; Harrington, Woolhandler, Mullan, Carrillo, \& Himmelstein, 2001; McGregor et al., 2005, 2010). This work has garnered particular attention because nurse staffing is often considered a proxy for the quality of resident care (Bostick, 2004; Schnelle et al., 2004). Residents in FP nursing homes have been shown to experience higher rates of hospitalization and mortality, as well as more frequent visits to emergency departments than residents in NFP homes (Comondore et al., 2009; Hillmer, Wodchis, Gill, Anderson, \& Rochon, 2005; McGregor et al., 2006; McGregor et al., 2014; Shapiro \& Tate, 1995; Tanuseputro et al., 2015). In the only national study on staffing in Canadian nursing homes (Berta et al., 2006), Ontario was found to have provided the fewest hours of RN care per resident day. In particular, FP facilities in this province had lower staffing levels than NFP and government-owned (i.e., municipal) facilities (Berta et al., 2005).
Of course, other organizational attributes - beyond FP and NFP status - may also influence staffing levels within nursing homes. One attribute that has received less attention in the Canadian LTC literature is chain affiliation. A rising number of nursing homes across Canada and the United States are operating as members of multi-facility chains (Banaszak-Holl, Berta, Bowman, Baum, \& Mitchell, 2002; Baum, 1999; Light, 1986). Between 1971 and 2011, the number of chainowned LTC homes in Ontario has increased eightfold, from 7 per cent (Baum, 1999) to 56 per cent (see Table 1) of all operating facilities. Baum (1999) argued that the expansion of chain operations in Ontario's LTC sector could be attributed to policy changes, intensified regulation of providers in this sector, and the current funding structure in this province; all of which favoured larger-scale operations. LTC homes that are owned and operated by a chain can benefit from economies of scale, which is manifested in formalized sharing of information, standardization of operational procedures, and preferential pricing from bulk purchasing of care supplies (Baum, 1999). In health care markets where profit margins and supply are restricted by government policies - as is the case for LTC in Ontario - these economic advantages are especially pertinent to the survival of private-sector operators.

Existing research on the differences in staffing level and quality of care between chain-owned and independent nursing homes is not as extensive as studies on profit status, and the limited literature in this area does not offer a clear conclusion. Although standardization of good clinical practice across facilities in a chain may improve some resident outcomes, such as declines in the percentage of residents with pressure ulcers (Anderson, Weeks, Hobbs, \& Webb, 2003; Kamimura et al., 2007), research from the United States has also found lower nurse staffing and a higher number of reported regulatory violations among chain operators (Harrington et al., 2001, 2012; Kim, Harrington, \& Greene, 2009a; Kim, Kovner, Harrington, Greene, \& Mezey, 2009b; O’Neill, Harrington, Kitchener, \& Saliba, 2003).

Studies of nursing home chains in Canada are sparse and have presented equally equivocal conclusions. McGregor et al. (2006) examined the care outcomes among nursing home residents in British Columbia and did not find a difference in the hospitalization or mortality rates between FP sub-groups (i.e., between FP 
Table 1: Profile of long-term care homes (LTCHs) in Ontario, by profit status and chain affiliation, 1996-1997 to 2010-2011

\begin{tabular}{|c|c|c|c|c|c|c|c|c|}
\hline \multirow[b]{2}{*}{ Characteristics of LTCHs } & \multicolumn{3}{|l|}{$\begin{array}{l}\text { For-Profit LTCHs } \\
(n=356)\end{array}$} & \multicolumn{3}{|c|}{$\begin{array}{l}\text { Not-For-Profit LTCHs } \\
(n=162)\end{array}$} & \multirow[t]{2}{*}{$\begin{array}{l}\text { Municipal LTCHs } \\
(n=109)\end{array}$} & \multirow{2}{*}{$\begin{array}{l}\text { All LTCHs in } \\
\text { Ontario } \\
(n=627)\end{array}$} \\
\hline & Chain Member & Independent & All & Chain Member & Independent & All & & \\
\hline Member of a chain (\%) & & & 82.7 & & & 38.5 & $\mathrm{n} / \mathrm{a}$ & 55.5 \\
\hline Number of beds per facility & $117.3[58.9]^{\mathrm{b}}$ & $79.5[41.6]^{b, h, i}$ & $109.0[58.0]^{\mathrm{d}, \mathrm{e}}$ & $118.6[73.4]^{i}$ & $116.2[83.2]^{\mathrm{h}}$ & $116.9[79.9]^{\mathrm{d}, \mathrm{f}}$ & $167.4[84.0]^{\mathrm{e}, \mathrm{f}}$ & $122.0[72.9]$ \\
\hline $\begin{array}{l}\text { Mean case-mix adjusted days } \\
\text { of care provided per facility } \\
\text { per year }(x 1,000)\end{array}$ & $41.7[20.6]^{\mathrm{b}}$ & $28.7[14.7] b, h, i$ & $38.9[20.3]^{d, e}$ & $42.5[25.9] \mathrm{i}$ & $41.7[29.5]^{\mathrm{h}}$ & $41.9[28.3] \mathrm{d}, \mathrm{f}$ & $59.7[29.8]^{e, f}$ & $43.6[25.7]$ \\
\hline Mean occupancy rate (\%) & $97.7[6.4]$ & $98.2[5.0]$ & $97.9[6.1]^{\mathrm{e}}$ & $98.4[3.6]$ & $98.0[5.8]$ & $98.1[5.1]$ & $98.4[3.5]^{\mathrm{e}}$ & $98.0[5.5]$ \\
\hline \multicolumn{9}{|c|}{ Distribution of residents by age (\%) } \\
\hline 65 years and older & $94.6[4.3] \mathrm{g}, \mathrm{i}$ & $94.8[3.8]$ & $94.6[4.2]^{d}$ & $95.5[3.8] \mathrm{g}$ & $95.5[6.8]^{\mathrm{i}}$ & $95.5[5.9]^{\mathrm{d}, \mathrm{f}}$ & $94.8[7.1]^{f}$ & $94.9[5.3]$ \\
\hline 75 years and older & $83.2[8.3] \mathrm{g}, \mathrm{i}$ & $83.2[8.6]^{h, i}$ & $83.2[8.3]^{d}$ & $85.7[8.2]^{g, i}$ & $86.6[10.6]^{\mathrm{h}, \mathrm{i}}$ & $86.3[9.9] d, f$ & $83.8[9.7]^{f}$ & $84.1[9.1]$ \\
\hline 85 years and older & $47.4[10.8]^{g, i}$ & $48.4[13.4]^{h, i}$ & $47.6[11.4]^{\mathrm{d}, \mathrm{e}}$ & $51.7[11.2]^{\mathrm{c}, g, i}$ & $54.7[14.1]^{\mathrm{c}, \mathrm{g}, \mathrm{i}}$ & $53.7[13.3]^{\mathrm{d}, \mathrm{f}}$ & $48.6[9.0] \mathrm{e}, \mathrm{f}$ & $49.3[11.8]$ \\
\hline \multicolumn{9}{|c|}{ Distribution of residents by level-of-care (\%) } \\
\hline Room \& Board & $0.4[0.4]$ & $0.6[0.4]$ & $0.4[0.3]$ & $0.06[0.03]$ & $0.2[0.3]$ & $0.1[0.2]$ & $0.2[0.1]$ & $0.3[0.2]$ \\
\hline Type I Care & $4.4[1.3]^{i}$ & $5.9[1.0]^{\mathrm{h}}$ & $4.7[1.2]^{\mathrm{d}, \mathrm{e}}$ & $4.9[2.1]^{c}$ & $8.5[5.7]^{\mathrm{c}, \mathrm{h}, \mathrm{i}}$ & $7.4[4.4]^{\mathrm{d}, \mathrm{f}}$ & $7.1[2.2]^{e, f}$ & $6.0[2.1]$ \\
\hline Type II Care & $64.6[6.1]^{\mathrm{b}, \mathrm{g}}$ & $63.5[7.8]^{b, h, i}$ & $64.5[5.7]^{\mathrm{e}}$ & $70.6[7.4]^{c, g, i}$ & $59.5[6.5]^{c, h}$ & $63.5[5.6]^{f}$ & $55.1[4.1]^{\mathrm{e}, \mathrm{f}}$ & $61.7[4.7]$ \\
\hline Type III Care & $29.8[5.5]^{\mathrm{b}}$ & $28.9[7.4]^{\mathrm{b}, \mathrm{h}}$ & $29.6[5.4]^{\mathrm{e}}$ & $23.9[6.7]$ & $31.2[8.4]^{\mathrm{h}}$ & $28.4[6.1]^{\mathrm{f}}$ & $36.4[3.5]^{e, f}$ & $31.1[4.6]$ \\
\hline Higher Type Care & $0.8[0.5]$ & 1.2 [0.7] & $0.8[0.5]^{\mathrm{e}}$ & $0.6[0.6]$ & $0.7[0.9]$ & $0.6[0.5]^{\mathrm{f}}$ & $1.2[1.1] \mathrm{e}, \mathrm{f}$ & $0.9[0.5]$ \\
\hline
\end{tabular}

Standard deviations are presented in braces.

$\mathbf{n} / \mathbf{a}=$ not applicable

a Includes facilities that were in operation for at least one year between 1996-1997 and 2010-2011 fiscal years

b Denotes a statistically significant difference between for-profit chain members and for-profit independent facilities at $p<0.05$

c Denotes a statistically significant difference between not-for-profit chain members and not-for-profit independent facilities at $p<0.05$

d Denotes a statistically significant difference between for-profit and not-for-profit facilities at $p<0.05$

e Denotes a statistically significant difference between for-profit and public facilities at $p<0.05$

$f$ Denotes a statistically significant difference between not-for-profit and public facilities at $p<0.05$

$g$ Denotes a statistically significant difference between for-profit and not-for-profit chain members at $p<0.05$

h Denotes a statistically significant difference between for-profit and not-for-profit independent facilities at $p<0.05$

i Denotes a statistically significant difference between for-profit chain members and not-for-profit independent facilities at $p<0.05$

i Denotes a statistically significant difference between not-for-profit chain members and for-profit independent facilities at $p<0.05$ 
chain, FP multi-site, and FP single-site operators). However, statistically significant differences on the same set of measures were found between NFP sub-groups; specifically, single-site operators had higher hospitalization rates due to falls, pneumonia, and dehydration than NFP multi-site operators. In Ontario, while McGregor et al. (2011) observed a significantly higher rate of verified complaints from residents in FP chains compared to non-profit care providers, Keays, Wister, and Gutman (2009) did not find a significant difference in the number of unmet operational standards by chain affiliation.

To our knowledge, staffing information by chain membership status has not been reported or published in Ontario.

\section{Research Objective}

Adding to the small collection of empirical research on staffing in the Canadian context (Berta et al., 2005', 2006; McGregor et al., 2005²), this article presents a longitudinal perspective of changes in staffing levels and the care needs of residents in Ontario's LTC homes. Longitudinal data consists of repeated measures from the same service providers, allowing us to assess whether observed patterns, outcomes, or correlations are consistent over time. Taking advantage of data collected over 15 years (from years 1996-1997 to 20102011), we examined the effect of profit status and chain operation on staffing, controlling for variation in the residents' case-mix. Results from this analysis can serve as the foundation for future empirical studies on health human resource planning, quality of care, and cost efficiencies in the LTC sector.

\section{Method}

\section{Data}

The Residential Care Facilities Survey (RCFS) is a longitudinal survey, annually administered by Statistics Canada to collect operational information from residential care providers across the country (Statistics Canada, 2012). Data collected through this survey may be used for program evaluation, policy development, budget planning, and research. The RCFS is the only data set with a national coverage of residential care facilities, and information on staffing within these settings.

Facilities included in our sample were RCFS respondents who have received funding from the Ontario Ministry of Health and Long-Term Care (MOHLTC) to provide nursing and personal care to their residents. This excludes other residential care providers who do not offer access to 24-hour nursing care, or who were not eligible to receive funding from the
MOHLTC for providing residential care (e.g., rest homes, retirement homes, supportive housing, and apartments for seniors).

To ensure that our sample was representative of the facilities that were funded and regulated by the MOHLTC, we validated the RCFS data against information obtained from the MOHLTC (MOHLTC, 2011). Comparing the total number of beds reported in the RCFS to figures from the Ministry's Health Data Branch, ${ }^{3}$ our sample captured 90.9 per cent of FP, 96.4 per cent of NFP, and 99.8 per cent of municipal LTC beds that were in operation between 2007 and 2011. Unfortunately, we were unable to validate data collected prior to 2007 as this information was not available.

In total, 627 LTC homes were included in this analysis. All facilities in our sample were in operation and had completed the RCFS in at least one data collection period between the 1996-1997 and 2010-2011 fiscal years.

\section{Definition of Variables}

We examined three types of ownerships in this study. The RCFS (Statistics Canada, 2011) defines a proprietary or FP facility as any organization or corporation owned by a private entity operating for a profit. Private NFP homes are facilities owned and operated by a religious or charitable organization on a nonprofit basis. Finally, municipal facilities are LTC homes that are owned and operated by any level of government (e.g., a city, county or municipal government, department of a provincial or territorial government, and/or federal department or agency). For our analysis, we have classified private NFP homes and municipal homes as distinct categories, which allowed us to compare the staffing levels between privately and publicly owned facilities operating on a non-profit basis.

Private FP and NFP homes were also characterized by their affiliation to a chain. Chain organizations are "collections of similar service [entities] ... linked together by common ownership", and where location is often the only difference between its members (Baum, 1999). Regardless of the organization's profit orientation, there seem to be advantages inherent to chain operations that have incentivized some facilities to adopt this structure. In our study, we defined chains as organizations with two or more LTC homes that shared the same business name and / or owner in a given data collection period. Facilities belonging to a chain were assigned a value of 1 ; independently operated homes were coded as 0 . The smallest chain in our sample had two members, whereas the largest chain had 58 members in the 2010 2011 fiscal year. 
The RCFS uses a level-of-care typology based on the hours and types of care that a resident requires (Statistics Canada, 2011). This scale was developed by Statistics Canada to ensure that consistent definitions were applied across jurisdictions and was used in this study as a measure of resident case-mix. Residents who receive room and board care in these facilities are expected to be relatively independent and require only minor supervision. Residents who receive Type I, Type II, and Type III Care require fewer than 90 minutes, between 1.5 to 2.5 hours, and greater than 2.5 hours of personal care per day, respectively. On top of personal support, Type II and Type III residents may also require access to 24-hour nursing and/or medical care. Residents who receive Higher Type Care $(<1 \%$ of residents in Ontario's LTC homes) are those who have unstable health conditions and require substantially more nursing and/or medical care than do residents under Type III Care. These categories are described in detail in the survey's official guide (Statistics Canada, 2011).

"Hours of care" was calculated by dividing the reported "total paid hours" for each type of staff by the number of resident care days provided in each data collection year. Total paid hours represents the sum of hours paid to all full-time, part-time, and casual employees who received salaries or wages from the facility. Staffing categories examined in our study include RNs, registered practical nurses (RPNs), health care aides (HCAs), ${ }^{4}$ therapists, ${ }^{5}$ and general services staff who provide administrative or operational support. Detailed descriptions of the types of direct care and support staff working in residential care facilities can be found in the survey's official guide (Statistics Canada, 2011).

Access to RCFS data was approved by Statistics Canada, and our analysis was conducted at the Toronto Region Research Data Centre (Toronto RDC). This project received ethics approval from the University of Toronto Research Ethics Committee.

\section{Analysis}

Descriptive statistics presented in this article provide a summary of the differences in resident case-mix and staffing levels over 15 years (1996-1997 to 2010-2011). The results are presented at the provincial level, and then stratified by profit status and chain affiliation. To account for variations in staffing due to the heterogeneity in case-mix, we predicted adjusted values using a random effects estimator whereby the observed "hours of care" was regressed on the distribution of residents (by age, sex, and level of care), as well as the data collection year. Pairwise comparisons of means by profit status and chain affiliation were conducted using the Scheffe method.

\section{Results}

Table 1 presents a profile of the LTC homes operating in Ontario between 1996 and 2011 by profit status and chain affiliation. Approximately 95 per cent of individuals admitted to these facilities were over the age of 65, or required at least 1.5 hours of personal care per day (see Table 1).

There were more FP homes in Ontario than NFP and municipal homes combined. FP homes made up approximately 56.8 per cent of all operating facilities in the province, but they had fewer beds on average $(p<0.001)$. The majority of the FP operators $(82.7 \%)$ were also members of a chain. In contrast, only 38.5 per cent of NFP homes belonged to a chain organization.

As shown in Figure 1, the number of LTC beds in this sector increased across all ownership types, with the largest increments observed in FP and NFP chain members. Since the 1996-1997 fiscal year, 15,080 LTC beds have been added to chain-owned FP homes, representing an increase of 88.3 per cent over 15 years. Across the same period, 4,354 beds were added to chain-owned NFP homes, corresponding to an increase of 134.6 per cent.

\section{Resident Care Needs}

Results from our pairwise comparison of means between the ownership categories suggest minor differences in the age distribution of the residents in these facilities and the level of care they required.

Distribution of Residents by Age

FP homes have a smaller percentage of residents over the age of 65 than do NFP $(p<0.001)$ and municipal homes $(p=0.670)$. Differences between chain members and independent homes operating under the same profit status were mostly non-significant. The only exception was in the proportion of residents over age 85 residing in NFP homes; independent NFP facilities had a higher percentage of residents who were over age 85 (by 3.0\%) than did NFP chain members $(p<0.001)$.

\section{Distribution of Residents by Level-of-Care}

Less than 1 per cent of residents in Ontario's LTC homes required only custodial care (i.e., room and board). The proportion of these residents did not differ significantly by profit status or chain affiliation (see Table 1).

Comparing the proportion of residents who received Type I Care across the ownership categories (see Table 1), FP homes had the smallest percentage of Type I Care residents $(p<0.001)$, and the difference between chainowned and independent FP facilities was not statistically significant. NFP chain members had 3.6 per cent 


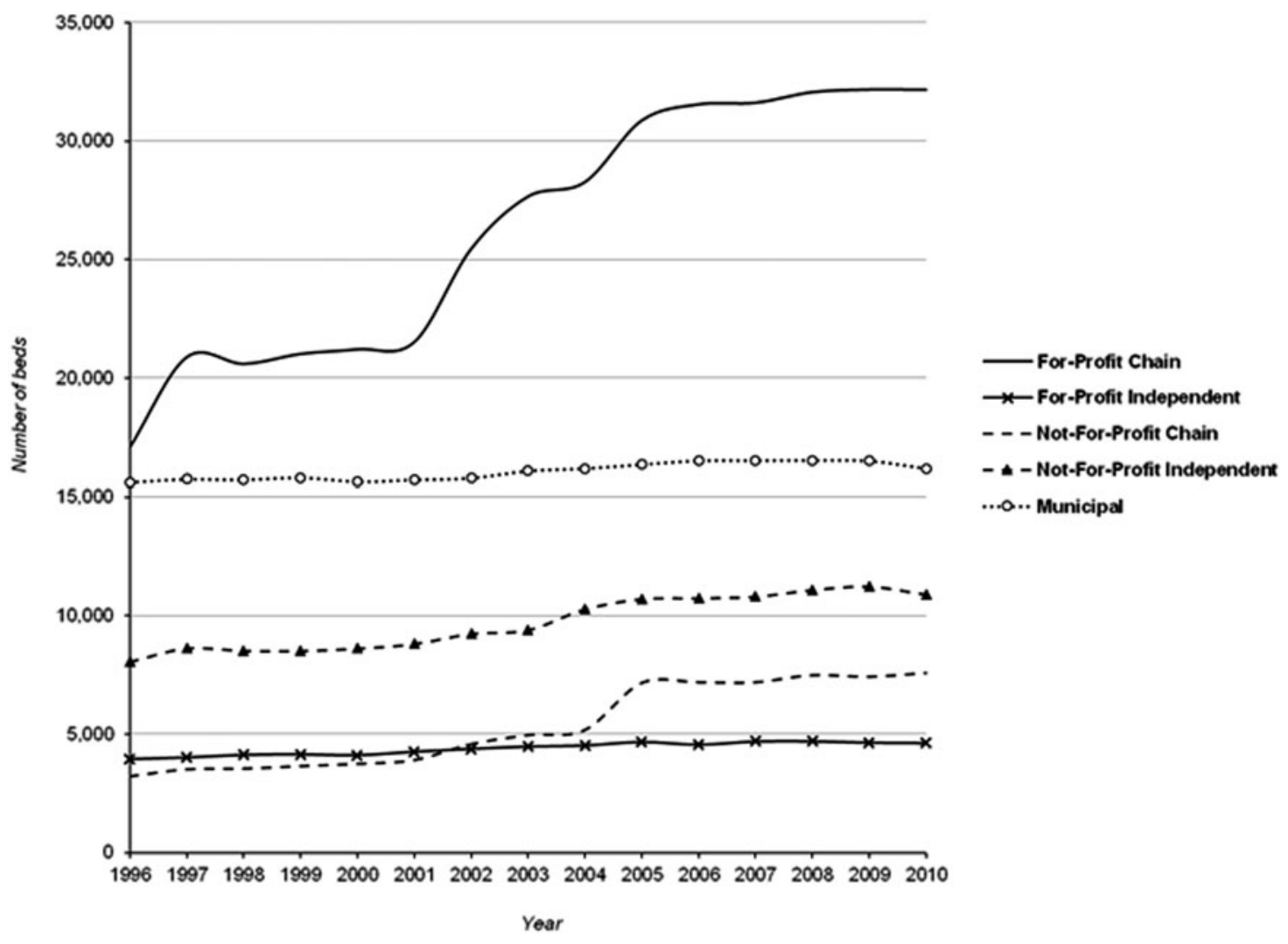

Figure 1: Distribution of LTC beds in Ontario, by profit status and chain affiliation

fewer residents at this care level than independent NFP homes $(p=0.001)$. In fact, independent NFP homes had a significantly larger percentage of residents requiring care at this level than other providers in this sector $(p<0.05)$. Overall, the number of Type I Care residents in Ontario's LTC homes declined by 18.3 per cent between 1996 and 2011.

The majority of the residents $(61.7 \%)$ required Type II Care (see Table 1). Compared to municipal LTC homes, Type II Care residents constituted a larger percentage of the care recipients in both FP and NFP facilities $(p<0.001)$. The proportions of Type II Care residents were also higher among chain-owned facilities, in comparison to their respective independent counterparts $(p<0.001)$. On the whole, the total number of residents requiring care at this level increased by 25.5 per cent between 1996 and 2011.

Approximately one third of residents in Ontario's LTC homes received Type III Care (see Table 1), and the number of residents who required this level of care increased by 114 per cent between 1996 and 2011. Although municipal LTC homes had a smaller proportion of Type II Care residents within their facilities, they had a significantly greater proportion of Type III Care residents than did FP and NFP homes $(p<0.001){ }^{6}$ There was also a higher percentage of Type III Care residents in chain-owned FP homes $(p<0.001)$, in comparison to their independent counterpart. The difference between chain-owned and independent NFP facilities was not statistically significant.

Between 1996 and 2011, the number of residents who required Higher Type Care increased by 164.3 per cent. However, LTC homes in Ontario have, on average, only one resident who required care at this level in any given year. The proportion of Higher Type Care residents in municipal LTC homes was significantly higher than both FP $(p<0.001)$ and NFP $(p<0.001)$ facilities. Differences by chain affiliation were not significant (see Table 1).

\section{Staffing Levels}

Table 2 presents the average staffing level by types of care personnel across the ownership categories. Figure 2 illustrates the annual change. Overall, the amount of care provided to residents in most staffing categories remained unchanged over our study period. The only notable difference was in the level of care provided by HCAs, which increased by 26.7 per cent.

Combining the total hours of direct care provided by RNs, RPNs, HCAs, and therapists, we determined that residents in municipal facilities received 0.08 hours or 
Table 2: Staffing level in Ontario's long-term care homes (LTCHs), mean hours of care per case-mix adjusted resident day, by profit status and chain affiliation, $1996-1997$ to 2010-2011

\begin{tabular}{|c|c|c|c|c|c|c|c|c|}
\hline \multirow[b]{2}{*}{ Types of Staff } & \multicolumn{3}{|l|}{ For-Profit LTCHs } & \multicolumn{3}{|c|}{ Not-For-Profit LTCHs } & \multirow[t]{2}{*}{ Municipal LTCHs } & \multirow[t]{2}{*}{ All LTCHs in Ontario } \\
\hline & Chain Member & Independent & All & Chain Member & Independent & All & & \\
\hline \multicolumn{9}{|l|}{ Direct Care } \\
\hline RNs & $0.37[0.15]^{a, h}$ & $0.42[0.16]^{a, g}$ & $0.38[0.15]^{c}$ & $0.39[0.19]^{\mathrm{b}}$ & $0.46[0.38]^{b, g, h}$ & $0.44[0.33]^{c, e}$ & $0.39[0.16]^{\mathrm{e}}$ & $0.40[0.21]$ \\
\hline RPNs & $0.39[0.31]^{f, h}$ & $0.41[0.28]^{g, i}$ & $0.40[0.31]^{c, d}$ & $0.52[0.47]^{f, i}$ & $0.54[0.57]^{g, h}$ & $0.53[0.53]^{c, e}$ & $0.72[0.57]^{d, e}$ & $0.49[0.45]$ \\
\hline HCAs & $1.66[0.57]$ & $1.65[0.65]$ & $1.65[0.58]^{\mathrm{c}}$ & $1.70[0.60]$ & $1.70[0.69]$ & $1.70[0.66]^{\mathrm{c}, \mathrm{e}}$ & $1.64[0.78]^{\mathrm{e}}$ & $1.66[0.64]$ \\
\hline Therapists & $0.21[0.19]^{\mathrm{h}}$ & $0.22[0.10]$ & $0.21[0.18]$ & $0.21[0.22]$ & $0.25[0.24]^{h}$ & $0.23[0.23]$ & $0.24[0.58]$ & $0.22[0.31]$ \\
\hline All Direct Care & $2.63[0.60]^{\mathrm{f}, \mathrm{h}}$ & $2.70[0.72] \mathrm{g}, \mathrm{i}$ & $2.64[0.62]^{c, d}$ & $2.82[0.64]^{b, f, i}$ & $2.95[1.00] \mathrm{b}, \mathrm{g}, \mathrm{h}$ & $2.90[0.89]^{\mathrm{c}, \mathrm{e}}$ & $2.98[0.88]^{\mathrm{d}, \mathrm{e}}$ & $2.77[0.77]$ \\
\hline \multicolumn{9}{|l|}{ Indirect Care } \\
\hline General Servicesi & $1.00[0.34]^{a, f}$ & $1.13[0.33]^{a, g, i}$ & $1.03[0.34]^{c, d}$ & $1.23[0.55]^{b, f, i}$ & $1.44[0.78]^{b, g}$ & $1.37[0.71]^{c, e}$ & $1.46[0.35]^{\mathrm{d}, \mathrm{e}}$ & $1.20[0.50]$ \\
\hline
\end{tabular}

Standard deviations are presented in parentheses. HCAs = health care aides; RNs = registered nurses; RPNs = registered practical nurses.

a Denotes a statistically significant difference between for-profit chain members and for-profit independent facilities at $p<0.05$

b Denotes a statistically significant difference between not-for-profit chain members and not-for-profit independent facilities at $p<0.05$

c Denotes a statistically significant difference between for-profit and not-for-profit facilities at $p<0.05$

d Denotes a statistically significant difference between for-profit and public facilities at $p<0.05$

e Denotes a statistically significant difference between not-for-profit and public facilities at $p<0.05$

f Denotes a statistically significant difference between for-profit and not-for-profit chain members at $p<0.05$

g Denotes a statistically significant difference between for-profit and not-for-profit independent facilities at $p<0.05$

h Denotes a statistically significant difference between for-profit chain members and not-for-profit independent facilities at $p<0.05$

i Denotes a statistically significant difference between not-for-profit chain members and for-profit independent facilities at $p<0.05$

i Includes personnel involved in administration, housekeeping, laundry, maintenance, facility operation, facility security, etc. 


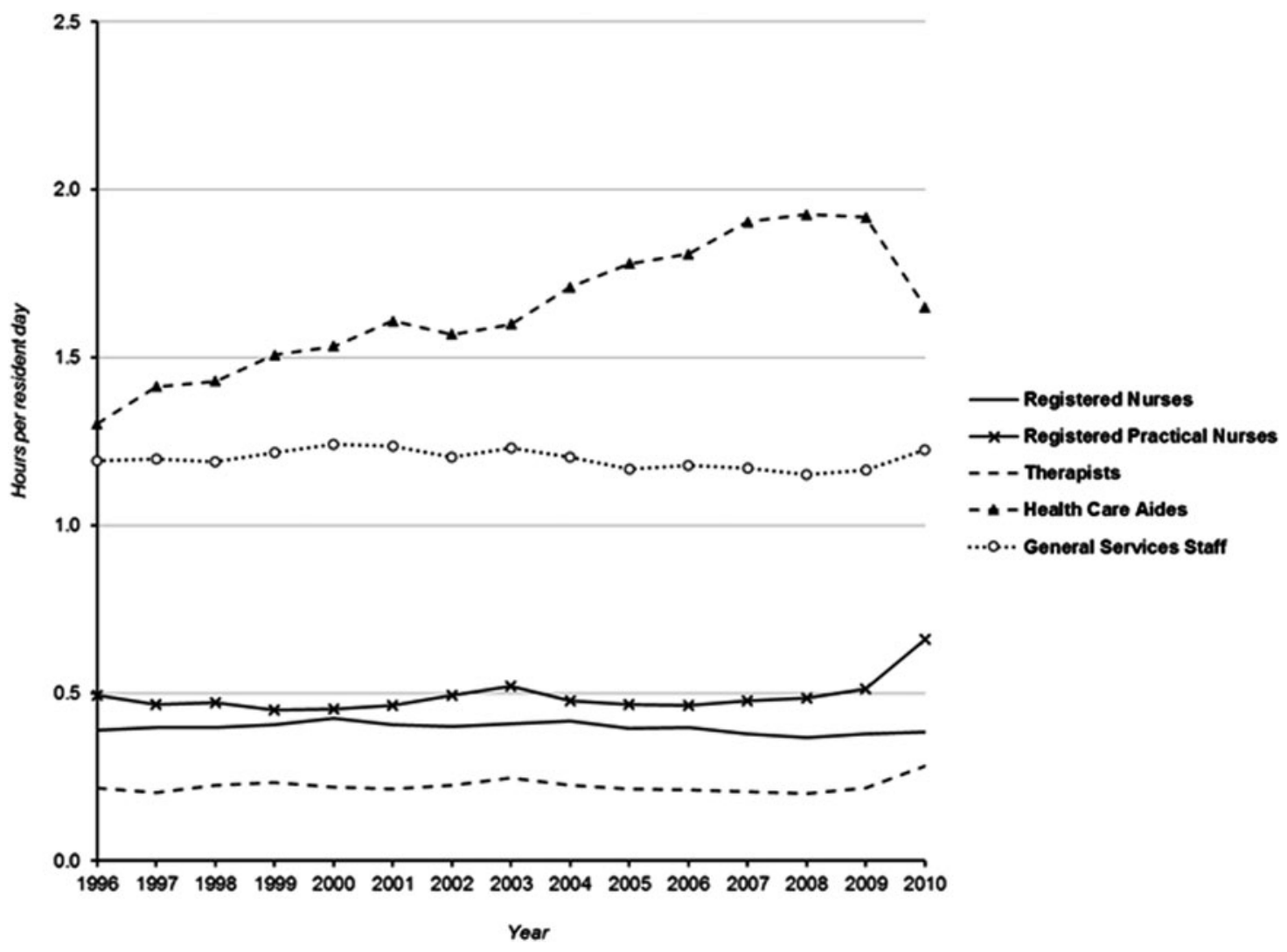

Figure 2: Hours of care per case-mix adjusted resident day, by types of staff

4.9 minutes more care per day than residents in NFP homes $(p=0.008)$. Compared to FP homes, residents in municipal facilities received an additional 0.34 hours or 20.5 minutes in direct care per day $(p<0.001)$. FP facilities - irrespective of chain affiliation - provided fewer hours of direct care than NFP facilities $(p<0.001)$.

FP chain members had the lowest staffing level in Ontario's LTC sector, at 2.63 hours of direct care per resident, per day. This was not significantly different from independently operated FP homes, likely due to the convergence in staffing levels among facilities operating under the same profit status over time (see Figure 3). Although direct care staffing in independent NFP homes was significantly higher than in NFP chain members $(p=0.008)$, staffing levels between these facilities have also converged over time.

\section{Registered Nurses}

Inequalities in RN staffing levels across ownership categories were minimal. RNs in Ontario's LTC homes provided approximately 0.40 hours or 23.8 minutes of care per resident day (see Table 2). FP chain members had the lowest RN staffing level among all operators, at 0.37 hours or 22.2 minutes per resident day. This was followed by NFP chain members and municipal homes, at 0.39 hours or 23.4 minutes per resident day each. Independent NFP homes had significantly higher RN staffing levels than other types of operators, at 0.46 hours or 27.6 minutes per resident day $(p<0.001)$. This is approximately equivalent to five additional minutes of $\mathrm{RN}$ care per resident day, in comparison to FP chains.

As shown in Figure 4, the hours of care provided by RNs in municipal homes and among FP chain members have increased by approximately 5 per cent (or 1.2 minutes per resident day) over our study period. Among other providers, RN staffing in Ontario's LTC sector has declined in recent years. The largest decrements were observed among independently owned FP and NFP homes, by 2.6 and 1.5 minutes per resident day, respectively.

\section{Registered Practical Nurses}

RPN staffing levels between the LTC homes demonstrated a greater divergence. Hours of care provided by RPNs was the highest among municipal LTC homes, at 0.72 hours or 43.2 minutes per resident day $(p<0.001)$. This was followed by NFP homes, at 0.53 hours or 31.9 minutes per resident day (see Table 2). Similar to RN staffing levels, FP chain members provided significantly fewer hours of RPN care than NFP and municipal LTC 


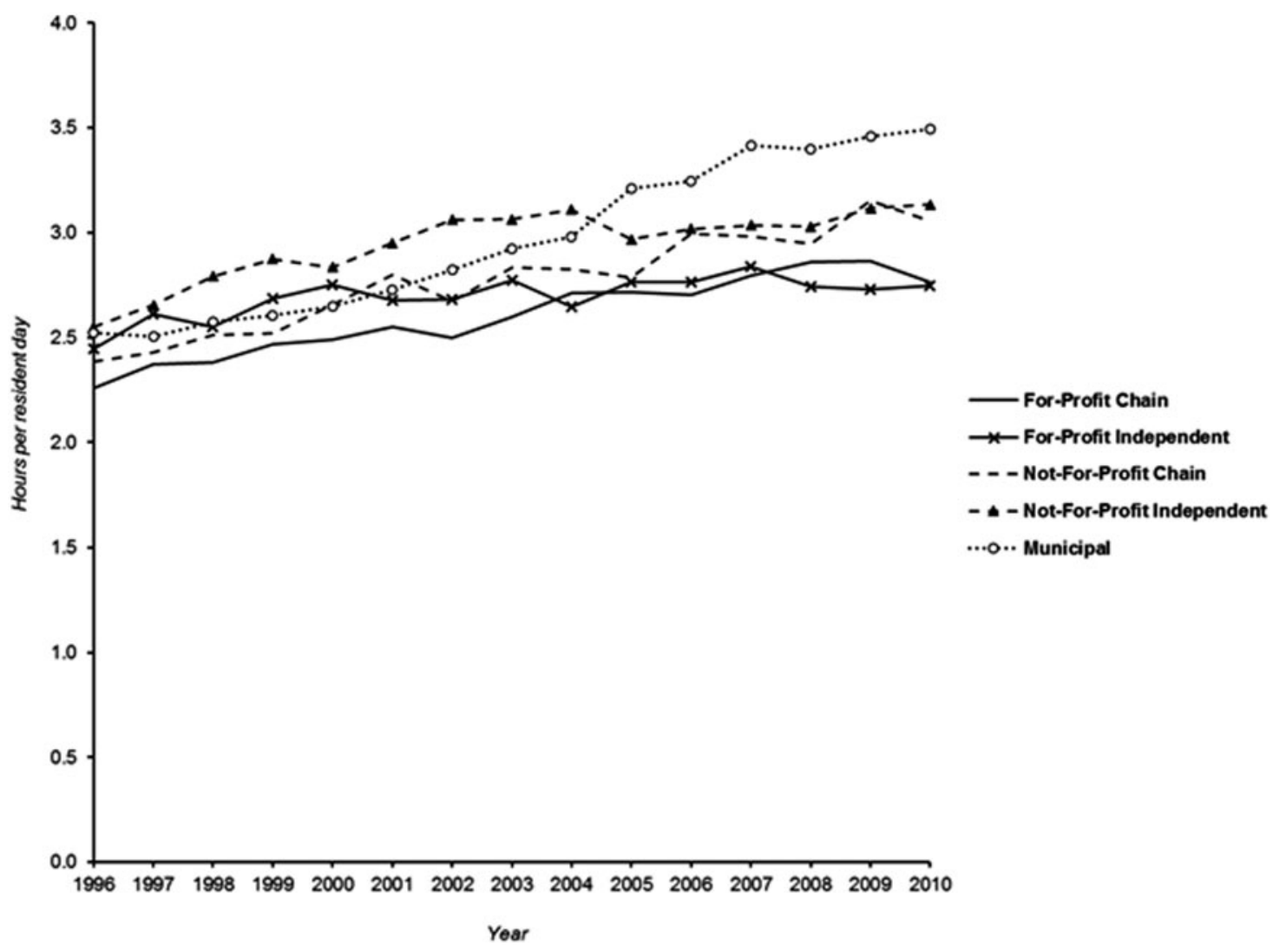

Figure 3: Hours of direct care per case-mix adjusted resident day, by profit status and chain affiliation

homes, at 0.39 hours or 23.4 minutes per resident day $(p<0.001)$. RPN staffing levels between chain-owned and independent homes operating under the same profit status did not differ significantly.

As shown in Figure 5, FP chain members experienced the greatest growth in RPN staffing over the 15-year period (by $81.0 \%$, or 18.3 minutes per resident day). Despite this increase, the RPN staffing level in FP chains was still lower than other types of providers. Similarly, while RPN staffing rose by 35.9 per cent among independent FP homes, the level of care provided in these facilities remained lower than levels observed in NFP and municipal homes.

The level of RPN care declined by 16.6 per cent or 7.3 minutes per resident day among NFP chain members over the study period. In contrast, we observed an 18.5 per cent increase (equivalent to 6.1 minutes per resident day) in independent NFP homes.

Although the RPN staffing level in municipal LTC homes has also expanded over the 15-year interval, it has been gradually declining since 2003. Between 2003 and 2010, the average RPN staffing level among these providers dropped from 0.80 to 0.73 hours per resident day; this represents an overall reduction of 4.3 minutes per resident day in these facilities.
Health Care Aides

Across the province, HCAs provided an average of 1.66 hours of care per resident, per day. NFP homes had the highest HCA staffing in Ontario's LTC sector; HCA staffing level in these facilities were, on average, 2.8 minutes higher than FP homes $(p=0.034)$ and 3.8 minutes higher than municipal homes $(p=0.016)$. However, the difference in the level of care provided by HCAs working in FP and municipal homes was not statistically significant. Differences between chain members and independently owned facilities operating under the same profit status were also not statistically significant.

Overall, HCA staffing level has increased in Ontario's LTC sector (Figure 2). NFP chain members experienced the greatest growth in HCA staffing - from 0.99 hours per resident day in 1996 to 1.79 hours in 2010 (see Figure 6). This was followed by municipal LTC homes, which increased by 45.6 per cent, from 1.28 to 1.87 hours. Changes in HCA staffing in FP homes were less than 15 per cent.

\section{Therapists}

Hours of care provided by therapists varied minimally between providers in Ontario's LTC sector. The only statistically significant difference $(p=0.021)$ was between 

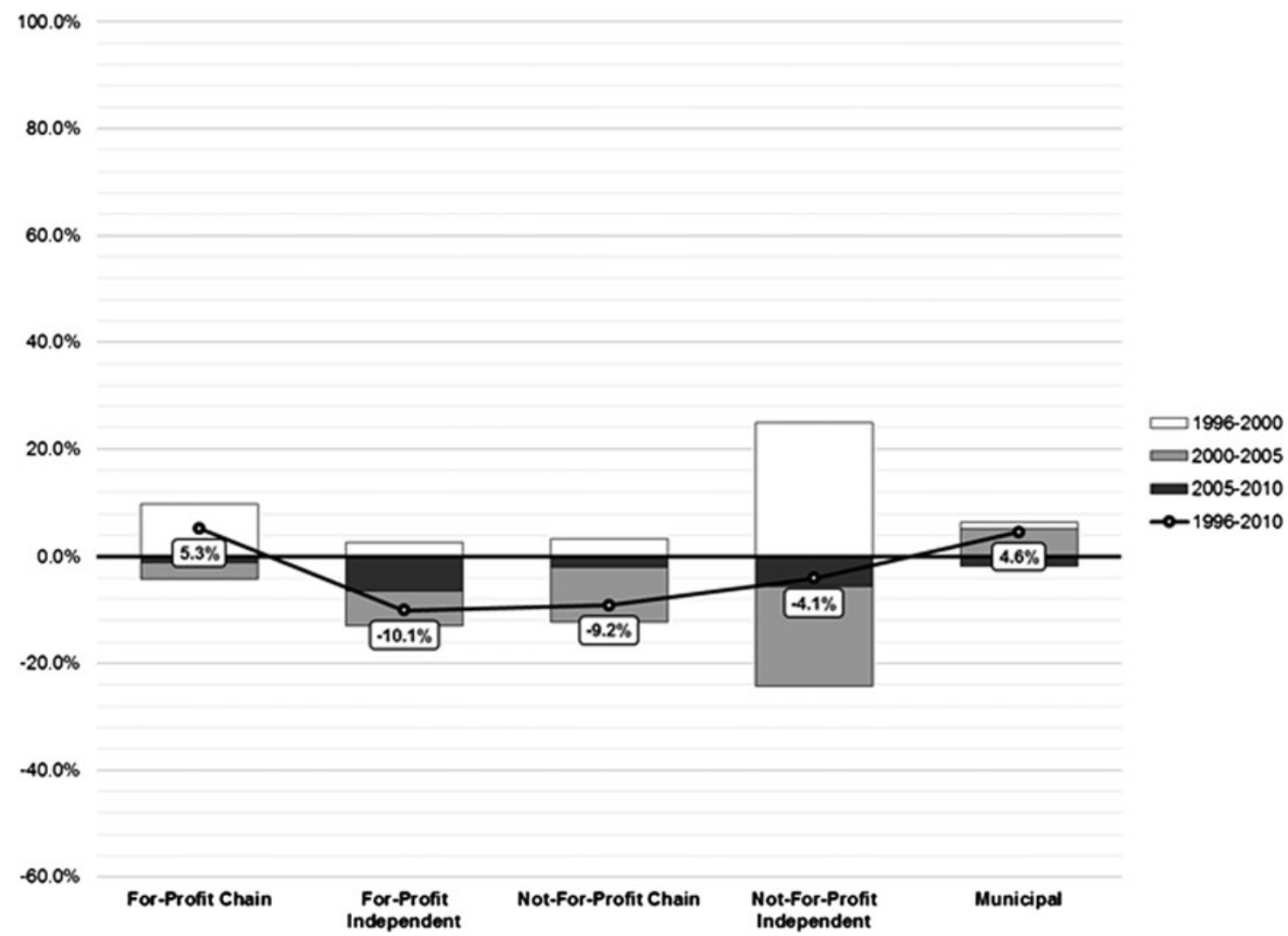

Figure 4: Change in hours of care by registered nurses per case-mix adjusted resident day, by profit status and chain affiliation

FP chain members and independently owned NFP homes; independent NFP homes provided 0.04 hours or 2.1 minutes of more therapeutic care per resident day than chain-owned FP homes. The provincial average was 0.22 hours or 13.4 minutes per resident day.

\section{General Services Staff}

Municipal LTC homes had the highest level of administrative and operational support in this sector. The level of support provided by general services staff in municipal LTC homes, which included RNs in administrative roles, was 1.46 hours per resident day $(p<0.001)$. Chain-owned FP and NFP facilities used, on average, four to eight fewer minutes of supportive services than their independent counterparts $(p<0.001)$.

\section{Discussion}

The results presented in this article raise important questions pertaining to how LTC is funded in Ontario and our capacity to meet the needs of those who receive care in this setting in the near future.

\section{Summary of Findings}

First, in light of our aging population, it was not surprising to have observed an increase in the level of care required by residents in Ontario's LTC homes over time.
However, the intensification of care needs may also be an artefact of the Aging at Home Strategy introduced in Ontario in 2007. The Aging at Home Strategy was an initiative launched by the McGuinty government to promote independent living among older Ontarians with less complex care needs, through increased investment in a wider range of publicly funded home and community services (Government of Ontario, 2013). Although this initiative has ensured that only the most frail are admitted into LTC homes, there has been no formal assessment of whether the direct care staff within these facilities were prepared, or sufficiently equipped, for these changes. Hence, as the needs of those who are cared for in these settings become more complex (Canadian Institute for Health Information [CIHI], 2011; CIHI, 2014), it is imperative that policy makers and researchers engage in ongoing evaluations of the adequacy of staffing levels in Ontario's LTC homes.

Second, as the population ages, we expect residents in LTC homes to require more nursing care than before. However, changes in RN staffing levels were marginal despite the rising proportion of residents with greater care needs. In contrast, care provided by HCAs - also known as personal support workers (PSWs) in Ontario experienced tremendous growth over the study period. This trend suggests that operators of LTC homes in Ontario were responding to the intensified care needs 


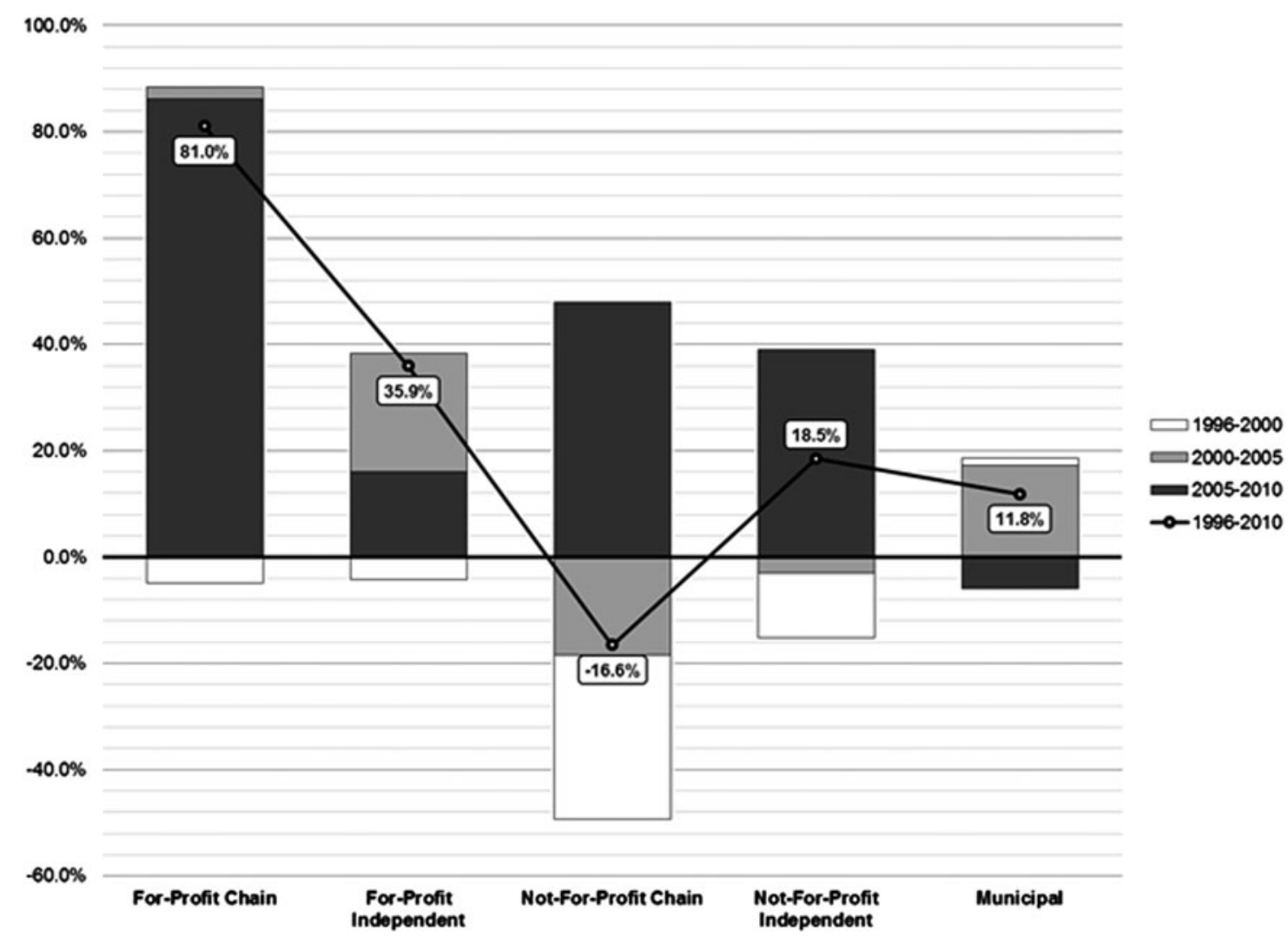

Figure 5: Change in hours of care by registered practical nurses per case-mix adjusted resident day, by profit status and chain affiliation

with augmented HCA support within their facilities. This observation is in line with findings from other Canadian studies, which have shown a rise in the number of care tasks delegated to health care support workers in LTC sectors across the country (Berta, Laporte, Deber, Baumann, \& Gamble, 2013; Zeytinoglu, Denton, Brookman, \& Plenderleith, 2014). Although HCAs working in this setting are better trained, and may be more prepared to meet the care needs of nursing home residents than before (Berta et al., 2013; Zeytinoglu et al., 2014), the impact of task shifting on the care outcomes of residents in these facilities is yet to be determined.

The lack of growth in $\mathrm{RN}$ care may be a reflection of the LTC homes' predisposition to operate at the minimum level required by legislation, in the interest of curtailing operating costs. Studies from the United States offer some evidence of labour substitution in nursing homes, whereby more costly care personnel may be replaced by less expensive labour in order to generate the same volume of care within constrained budgets (Bowblis \& Hyer, 2013; Chen \& Grabowski, 2015). A recent study by Hsu, Berta, Coyte, Rohit Dass, \& Laporte (2015) also offers some indication to labour substitution (between RPNs and HCAs) in Ontario's LTC sector. Alternatively, operators may be restricted in their capacity to improve staffing levels, given recent declines in the number of nurses entering the LTC sector in Ontario (Alameddine et al., 2006). In all likelihood, both factors may have contributed to the lack of growth in RN care in this sector, and have some implications for the LTC homes' capacity to increase RN care in this setting in the future.

Since 2007, there has been an observed increase in $\mathrm{RPN}$ care across the province. This trend may be a result of the Ontario government's commitment to create new RPN positions in the LTC sector, specifically to address the rising demand for health care among older Ontarians (Government of Ontario, 2007). Despite the province-wide investment in RPN staffing, the uptake appears to be unevenly distributed across the ownership categories; residents in municipal facilities received nearly twice the amount of RPN care compared to residents in FP facilities. Moreover, the variation in RPN staffing levels across ownership categories have a strong influence over the observed differences in direct care staffing levels in this sector - as RN, HCA, and therapist staffing levels were similar among facilities operating under different ownerships.

In theory, profit status should not have a significant effect on staffing levels, once resident characteristics 


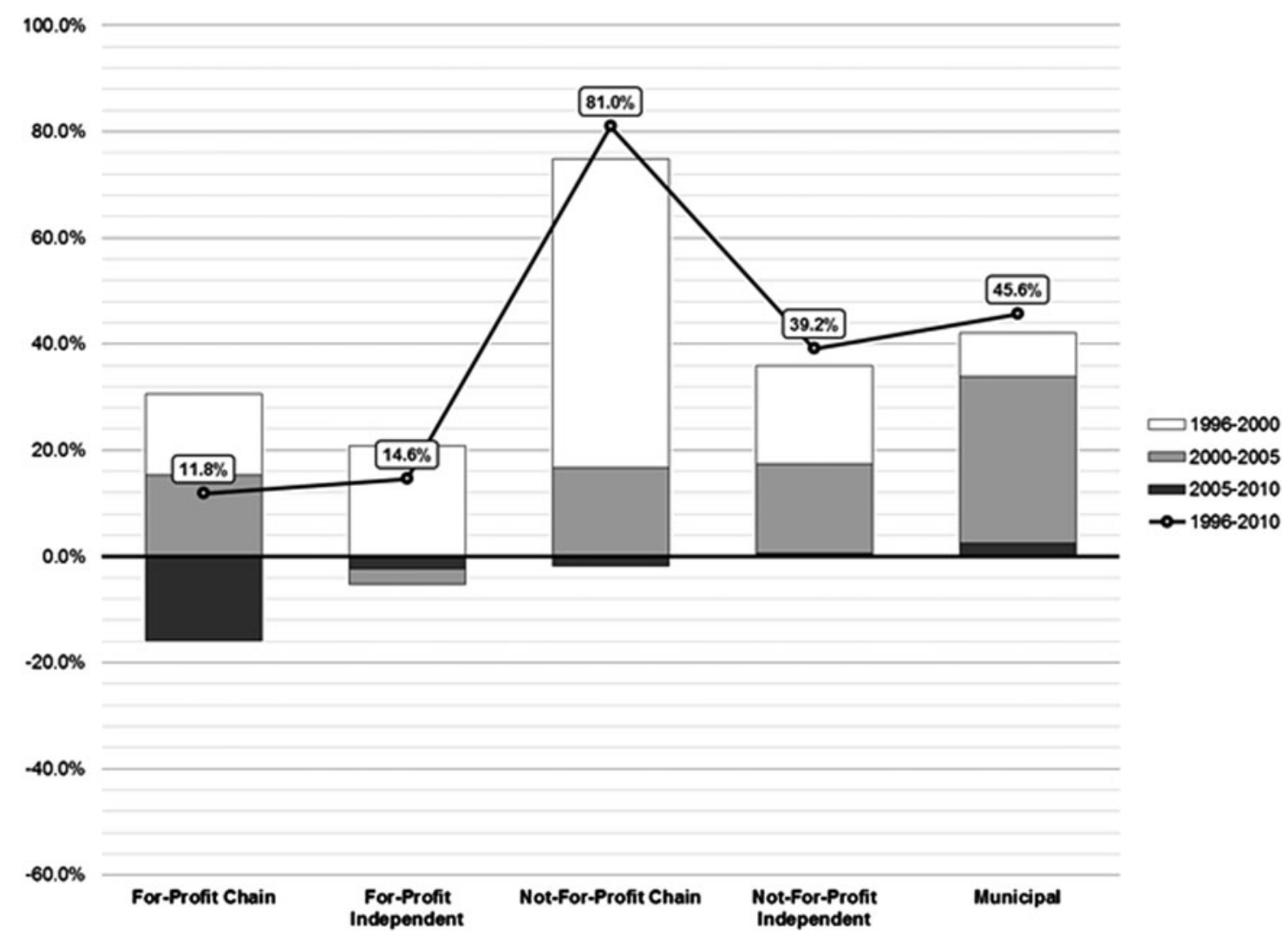

Figure 6: Change in hours of care by health care aides per case-mix adjusted resident day, by profit status and chain affiliation

have been accounted for. Nursing and personal care provided in Ontario's LTC homes are funded through casemix adjusted per diem payments from the MOHLTC. Over the timeframe analysed in this study, the Ministry applied the Alberta Resident Classification System (ARCS) for categorizing residents into various dependency groups. Based on the average acuity within the facility, adjustments are made to the base per diem rate set by the Ministry. This process ensures that resources are allocated equitably and match the needs of the residents. However, as shown by the results of our study, variations in staffing by profit status continued to exist. This was a consistent finding across all staffing categories. Given the same per diem funding, municipal LTC homes were able to provide the highest volume of direct care in Ontario's LTC sector, and homes that operated on a non-profit basis (i.e., by private NFP and municipal LTC homes) provided more care to their residents than FP facilities. Furthermore, we found that staffing levels also varied significantly by chain affiliation.

Our analysis revealed statistically significant differences in nurse staffing levels between chain-owned and independent LTC homes in Ontario. Similar to chain-owned nursing homes in the United States (Harrington et al., 2012), FP chain members in Ontario provided fewer hours of RN and RPN care than the provincial average. In addition, we also found lower RN and RPN staffing levels among chain-owned NFP homes, compared to independently owned NFP homes. On average, residents in municipal LTC homes received 20 minutes more direct care per day than those residing in chain-owned FP homes. Given that one of the advantages of chain operation is standardization of administrative processes, it was not surprising that chain-owned LTC homes used fewer hours of support services per resident day than their independent counterparts.

\section{Policy Implications}

Studies conducted in the United States have shown strong associations between higher direct care staffing levels and better health outcomes among nursing home residents (Bostick, 2004; Castle, 2008; Harrington, Zimmerman, Karon, Robinson, \& Beutel, 2000; Konetzka, Stearns, \& Park, 2008; Schnelle et al., 2004). Facilities with inadequate staffing are often unable to meet even the basic care needs of residents, such as providing at least one bath a week, sufficient changes of incontinent products, and regular assistance with mobility or other activities (Smith, 2004). Prior research indicates that assisting a resident with toileting takes on average 8 minutes to complete (Schnelle, Sowell, Traughber, \& Hu, 1988), and feeding takes between 35 to 40 minutes per resident 
each meal (Simmons \& Schnelle, 2006). Medication administration by RNs required approximately 62 minutes per 20 residents (Thomson et al., 2009). Therefore, we suspect the additional care provided in municipal homes may be associated with better health outcomes and quality of life among its residents, although we were unable to formally investigate this relationship using the RCFS data.

The findings presented in this article raise interesting questions about the roles of each type of staff within the LTC homes, and the dynamic between them. It is possible that, in the absence of regulated staffing standards (for RPNs and HCAs), facility operators may choose a less costly mix. Although the results presented here cannot directly speak to the impact of lower staffing levels on health outcomes of residents in Ontario's LTC homes, or affirm that lower staffing levels were driven by the profit imperative of some operators, this study highlights the importance of examining chain affiliation in addition to profit status in the Canadian context. Moreover, to ensure that high-quality care is actually provided in this setting, there would need to be greater oversight of the outcomes of care and less focus on the isolated productivity of one or two types of care staff.

\section{Limitations}

Like other self-reported surveys, the RCFS is susceptible to response bias. However, validation of financial information reported in the RCFS against public accounts suggests that the information is consistent across sources (Hicks, Fortin, \& Button, 2002). Second, the category of "other direct care" staff in the RCFS may include hours paid to nursing aides, health care aides, dieticians, counsellors, orderlies, social workers, graduate nurses, and chaplains. Since PSWs constitute the largest group of care personnel staffed in Ontario's LTC homes (Armstrong \& Daly, 2004; Sharkey, 2008), we believe the conclusion presented here is a reasonable representation of changes in this workforce. Finally, the administrative structure of the RCFS limited our ability to examine the relationship between staffing levels and health outcomes among residents in Ontario's LTC homes. This shortcoming can be addressed in the future, through linkages of staffing and health administrative data. Unfortunately, with the termination of the RCFS in 2012 (Statistics Canada, 2012), the opportunities to explore these relationships may be limited.

\section{Conclusion}

Results presented in this article expand our understanding of the impact that organizational structure has on staffing in Ontario's LTC homes. We observed significant differences in staffing levels and mix across FP,
NFP, and municipal homes, and by chain ownership. Residents in municipal homes received, on average, 20 minutes more of direct care per day, compared to those residing in FP chain homes. Moreover, municipal operators were able to achieve this by providing more hours of RPN care than other types of operators, controlling for variation in the care needs of the residents in these facilities. Results presented in this article point to the need for a better understanding of care delivery models, and of how more effective staffing mix is achieved among some operators (e.g., municipal homes). Furthermore, Ontario is not the only jurisdiction that has witnessed a growing presence of chain organizations in its LTC sector. Our findings also recommend future research on the process by which resources and knowledge are transferred between component facilities within a chain, and examination of the impact of chain operation on other measures of quality of care.

\section{Notes}

1 Through extensive record matching with the directory of long-term care homes obtained from Ministry of Health and Long-Term Care (MOHLTC), and cross-referencing of information in the Guides to Canadian Healthcare Facilities published from 1999-2000 and 2010-2011 (available publicly through the Toronto Public Library and the University of Toronto Libraries), we eliminated additional facilities that did not provide publicly funded 24-hour nursing and personal care from the sample used by Berta et al. (2005). Furthermore, their study presented crude staffing levels, without adjusting for the residents' care needs. Consequently, figures presented in this article are not directly comparable to results published in Berta et al. (2005).

2 McGregor et al. (2005) presented a cross-sectional analysis of staffing levels in long-term care facilities in British Columbia, but did not distinguish private NFP facilities from government-operated facilities - likely due to small sample size. As shown in other studies from British Columbia, there are noticeably fewer public or health region-owned facilities than Ontario (McGregor et al., 2010; McGregor et al., 2011). The study by McGregor et al. (2005) also did not stratify private NFP facilities by chain membership status.

3 Accessible from the Ontario Long-Term Care Association's (OLTCA) “Data Reports" webpage (http://www.oltca. com/data-reports).

4 HCAs are increasingly referred to as personal support workers (PSWs) in Ontario. However, on the basis of the description provided in the survey's official guide (Statistics Canada, 2011), the category of "other direct care" staff may include nursing aides, health care aides, personal support workers, dieticians, counsellors, orderlies, social workers, graduate nurses, and chaplains. Based on existing knowledge about Ontario's LTC sector (Armstrong \& Daly, 2004; Sharkey, 2008), we believe this variable mostly reflects the hours of care provided by PSWs, who provide direct assistance to RNs and RPNs in resident care. 
5 For this study, hours of work paid to physiotherapists, occupational therapists, and other therapists, as well as activity/recreation staff, were combined and collectively reported under the category of "therapists".

6 In line with the growth of private-sector care providers in Ontario, the number of Type III Care residents who have received care in municipal facilities declined in recent years (data not shown). Municipal LTC homes provided care to 38.3 per cent of the Type III Care residents in 1996, but this had since declined to 22.6 per cent (in 2010-2011). FP chain homes provided care to 32.4 per cent of Type III Care residents in 1996, but their share in the LTC sector had gradually increased to 45.9 per cent over the 15 years. Among NFP chain homes, the proportion increased from 7.4 to 8.3 per cent of all Type III Care residents.

\section{References}

Alameddine, M., Laporte, A., Baumann, A., O'Brien-Pallas, L., Croxford, R., Mildon, B., et al. (2006). Where are nurses working? Employment patterns by sub-sector in Ontario, Canada. Healthcare Policy, 1(3), 65-86.

Anderson, R. I., Weeks, H. S., Hobbs, B. K., \& Webb, J. R. (2003). Nursing home quality, chain affiliation, profit status and performance. Journal of Real Estate Research, 25(1), 43-60.

Armstrong, P., \& Daly, T. (2004). There are not enough hands. Markham, ON: CUPE Ontario.

Banaszak-Holl, J., Berta, W., Bowman, D. M., Baum, J., \& Mitchell, W. (2002). The rise of human service chains: Antecedents to acquisitions and their effects on the quality of care in US nursing homes. Managerial and Decision Economics, 23(4-5), 261-282.

Banaszak-Holl, J., \& Hines, M. A. (1996). Factors associated with nursing home staff turnover. The Gerontologist, $36(4), 512-517$.

Baum, J. (1999). The rise of chain nursing homes in Ontario, 1971-1996. Social Forces, 78(2), 543-583.

Berta, W., Laporte, A., Deber, R., Baumann, A., \& Gamble, B. (2013). The evolving role of health care aides in the longterm care and home and community care sectors in Canada. Human Resources for Health, 11(1), 25.

Berta, W., Laporte, A., \& Valdmanis, V. (2005). Observations on institutional long-term care in Ontario: 1996-2002. Canadian Journal on Aging, 24(1), 71-84.

Berta, W., Laporte, A., Zarnett, D., Valdmanis, V., \& Anderson, G. (2006). A pan-Canadian perspective on institutional long-term care. Health Policy, 79(2-3), 175-194.

Blomqvist, Å., \& Busby, C. (2012). Long-term care for the elderly: Challenges and policy options. (Commentary No. 367). Toronto, ON: C. D. Howe Institute.

Bostick, J. E. (2004). Relationship of nursing personnel and nursing home care quality. Journal of Nursing Care Quality, 19(2), 130-136.
Bowblis, J. R., \& Hyer, K. (2013). Nursing home staffing requirements and input substitution: Effects on housekeeping, food service, and activities staff. Health Services Research, 48(4), 1539-1550.

Bravo, G., Charpentier, M., Dubois, M., De Wals, P., \& Émond, A. (1998). Profile of residents in unlicensed homes for the aged in the eastern townships of Québec. CMAJ, 159(2), 143-148.

Canadian Institute for Health Information (CIHI). (2011). Health care cost drivers: The facts. Ottawa, ON: Author.

Canadian Institute for Health Information (CIHI). (2014). CCRS Profile of Residents in Continuing Care Facilities [Data files]. Retrieved 13 October 2014 from http:// www.cihi.ca/CIHI-ext-portal/internet/EN/Quick_ Stats / quick+stats / quick_stats_main?pageNumber $=1 \&$ resultCount $=10$

Castle, N. (2008). Nursing home caregiver staffing levels and quality of care: A literature review. Journal of Applied Gerontology, 27(4), 375-405.

Chen, M., \& Grabowski, D. (2015). Intended and unintended consequences of minimum staffing standards for nursing homes. Health Economics, 24(7), 822-839.

Comondore, V. R., Devereaux, P. J., Zhou, Q., Stone, S. B., Busse, J. W., Ravindran, N. C., et al. (2009). Quality of care in for-profit and not-for-profit nursing homes: Systematic review and meta-analysis. BMJ, 339(7717), 381.

Government of Ontario. (2007). McGuinty government celebrates the creation of 8,000 new nursing positions. Retrieved 20 September 2014 from http:/ /news.ontario.ca/archive/ en/2007/05/09/McGuinty-government-celebrates-thecreation-of-8000-new-nursing-positions.html

Government of Ontario. (2013). Independence, activity and good health: Ontario's Action Plan for Seniors. Retrieved 19 April 2014 from http://www.ontario.ca/seniors / ontarios-action-plan-seniors

Harrington, C., Olney, B., Carrillo, H., \& Kang, T. (2012). Nurse staffing and deficiencies in the largest for-profit nursing home chains and chains owned by private equity companies. Health Services Research, 47(1), 106-128.

Harrington, C., Woolhandler, S., Mullan, J., Carrillo, H., \& Himmelstein, D. U. (2001). Does investor ownership of nursing homes compromise the quality of care? American Journal of Public Health, 91(9), 1452-1455.

Harrington, C., Zimmerman, D., Karon, S. L., Robinson, J., \& Beutel, P. (2000). Nursing home staffing and its relationship to deficiencies. Journal of Gerontology: Social Sciences, $55 B(5)$, S278-S287.

Hicks, V., Fortin, G., \& Button, I. (2002). Long term residential care in National Health Expenditures: Feasibility study. Ottawa, ON: Canadian Institute for Health Information.

Hillmer, M. P., Wodchis, W. P., Gill, S. S., Anderson, G. M., \& Rochon, P. A. (2005). Nursing home profit status and 
quality of care: Is there any evidence of an association? Medical Care Research and Review, 62(2), 139-166.

Hsu, A. T., Berta, W., Coyte, P. C., Rohit Dass, A., \& Laporte, A. (2015). Productivity and substitutability of labor within nursing homes in Ontario, Canada: An analysis using longitudinal data (Working Paper Series). Toronto, ON: Canadian Centre for Health Economics.

Kamimura, A., Banaszak-Holl, J., Berta, W., Baum, J., Weigelt, C., \& Mitchell, W. (2007). Do corporate chains affect quality of care in nursing homes? The role of corporate standardization. Health Care Management Review, 32(2), 168-178.

Keays, S., Wister, A. V., \& Gutman, G. M. (2009). Administrators and quality of care in long-term care facilities. Journal of Housing for the Elderly, 23, 243-260.

Kim, H., Harrington, C., \& Greene, W. H. (2009a). Registered nurse staffing mix and quality of care in nursing homes: A longitudinal analysis. The Gerontologist, 49(10), 81-90.

Kim, H., Kovner, C., Harrington, C., Greene, W. H., \& Mezey, M. (2009b). A panel data analysis of the relationships of nursing home staffing levels and standards to regulatory deficiencies. Journal of Gerontology: Social Sciences, 64B(2), 269-278.

Konetzka, R. T., Stearns, S. C., \& Park, J. (2008). The staffingoutcomes relationship in nursing homes. Health Services Research, 43(3), 1025-1042.

Light, D. W. (1986). Corporate medicine for profit. Scientific American, 255(6), 38-45.

McGregor, M. J., Abu-Laban, R. B., Ronald, L. A., McGrail, K. M., Andrusiek, D., Baumbusch, J., et al. (2014). Nursing home characteristics associated with resident transfers to emergency departments. Canadian Journal on Aging, $33(1), 38-48$.

McGregor, M. J., Cohen, M., McGrail, K., Broemeling, A. M., Adler, R. N., Schulzer, M., et al. (2005). Staffing levels in not-for-profit and for-profit long-term care facilities: Does type of ownership matter? CMAJ, 172(5), 645-649.

McGregor, M. J., Cohen, M., Stocks-Rankin, C., Cox, M. B., Salomons, K., McGrail, K. M., et al. (2011). Complaints in for-profit, non-profit and public nursing homes in two Canadian provinces. Open Medicine, 5(4), e183-192.

McGregor, M. J., Tate, R. B., McGrail, K. M., Ronald, L. A., Broemeling, A., \& Cohen, M. (2006). Care outcomes in long-term care facilities in British Columbia, Canada: Does ownership matter? Medical Care, 44(10), 929-935.

McGregor, M. J., Tate, R. B., Ronald, L. A., McGrail, K. M., Cox, M. B., Berta, W., et al. (2010). Trends in long-term care staffing by facility ownership in British Columbia, 1996 to 2006. Health Reports, 21(4), 27-33.
O’Neill, C., Harrington, C., Kitchener, M., \& Saliba, D. (2003). Quality of care in nursing homes: An analysis of relationships among profit, quality, and ownership. Medical Care, 41(12), 1318-1330.

Ontario Ministry of Health and Long-Term Care (MOHLTC). (2011). Reports on long-term care homes. Retrieved 20 November 2010 from http://publicreporting.ltchomes. net/en-ca/default.aspx

Schnelle, J. F., Simmons, S. F., Harrington, C., Cadogan, M., Garcia, E., \& Bates-Jensen, B. M. (2004). Relationship of nursing home staffing to quality of care. Health Services Research, 39(2), 225-250.

Schnelle, J. F., Sowell, V. A., Traughber, B., \& Hu, T. (1988). A behavioral analysis of the labor cost of managing continence and incontinence in nursing home patients. Journal of Organizational Behavior Management, 9(2), 137-153.

Shapiro, E., \& Tate, R. B. (1995). Monitoring the outcomes of quality of care in nursing homes using administrative data. Canadian Journal on Aging, 14(4), 755-768.

Sharkey, S. (2008). People caring for people: Impacting the life and care of residents of long-term care homes. Toronto, ON: Ontario Ministry of Health and Long-Term Care.

Simmons, S. F., \& Schnelle, J. F. (2006). Feeding assistance needs of long-stay nursing home residents and staff time to provide care. Journal of the American Geriatrics Society, 54(6), 919-924.

Smith, M. (2004). Commitment to care: A plan for long-term care in Ontario. Toronto, ON: Ontario Ministry of Health and Long-Term Care.

Statistics Canada. (2011). Residential Care Facilities Survey-2010 (Guide). Ottawa, ON: Author.

Statistics Canada. (2012). Residential Care Facilities (RCF). Retrieved 18 July 2012 from http://www23.statcan. gc.ca $/$ imdb /p2SV.pl?Function=getSurvey\&SDDS=3210 \&lang $=$ en $\& d b=$ imdb\&adm $=8 \&$ dis $=2$

Tanuseputro, P., Chalifoux, M., Bennett, C., Gruneir, A., Bronskill, S. E., Walker, P., et al. (2015). Hospitalization and mortality rates in long-term care facilities: Does for-profit status matter? Journal of the American Medical Directors Association, 16(10), 874-883.

Thomson, M. S., Gruneir, A., Lee, M., Baril, J., Field, T. S., Gurwitz, J. H., et al. (2009). Nursing time devoted to medication administration in long-term care: Clinical, safety, and resource implications. Journal of the American Geriatrics Society, 57(2), 266-272.

Zeytinoglu, I. U., Denton, M., Brookman, C., \& Plenderleith, J. (2014). Task shifting policy in Ontario, Canada: Does it help personal support workers' intention to stay? Health Policy, 117(2), 179-186. 